\title{
TWO-COMBUSTOR TURBOFAN ENGINE PERFORMANCE ANALYSIS
}

\author{
Robert Jakubowski \\ Department of Aircrafts and Aircraft Engines \\ Rzeszow University of Technology \\ Powstancow Warszawy Av. 8, 35-959 Rzeszow, Poland \\ tel.: +48178651466 fax +48178651942 \\ e-mail: robert.jakubowski@prz.edu.pl
}

\begin{abstract}
A conception of a two-combustor turbofan engine is the main scope of this paper. At the beginning, the problems of turbofan engines development are briefly discussed as a background of this work. In this part the turbofan engines innovation activities are presented. It is mentioned the engine's innovations consists of many aspects but some important ones are: lowering of production operation cost, maintenance, reduction of noise and exhaust gases emission while engine reliability should stay on the same level or event increase. Next, the conception of turbofan engine with two combustors is presented in this context. Some positive aspects for environment, production and maintenance of such engine are discussed. Then the thermodynamic cycle of two-combustor engine is presented and analysed. On this basis, the engine numerical model is prepared. Next, some information about the model simplifications and calculations done to determine performance of the engine is presented. Then the results of the simulation calculations of the engine performance are presented and discussed. The relationship of engine thrust and specific fuel consumption vs. engine flight conditions are shown. Based on the results there were discussed the advantages and disadvantages of two combustors engine as an airplane propulsion are specified. The conclusions are formulated and presented in the last part of the paper.
\end{abstract}

Keywords: jet engine, turbofan engine, engine performance, airplane engine development

\section{Introduction}

The aircraft transport has been strongly developing for last years. New modern aircrafts have been introduced into the service. They give better flight comfort for passengers and should be more friendly for environment. One of a main factor of this progress is propulsion development. Modern engines have low fuel consumption and generate less noise and pollution emission. The engine improvements activity is still continuous. The new conceptions of propulsions are developed and studied. Some works concentrate on the engine with inter-stage burning. Realised analyses show the higher efficiency of such engine than classical turbojet or turbofan engines [8, 9]. Some advantages of such engine conception with two combustors were discussed in paper [4, 6-9]. It was shown that this engine could be more efficient, reliable and lower $\mathrm{NO}_{\mathrm{X}}$ emission by turbine inlet temperature reduction than classical turbofan one.

The performances of two combustor engines are studied in this paper. The numerical model is briefly presented. The engine performance is calculated, presented and discussed.

\section{Two combustors engine}

In the paper, the comparison of classical turbofan engine and turbofan two combustors engine is presented in. A two-combustor turbofan engine has an additional combustor between high and low pressure turbine (see Fig. 1). It is called inter-turbine burner [8, 9]. The other elements of such engine are similar to the classical turbofan engine. It consist of: an inlet, fan, splitter separated stream for external and internal duct, compressors, turbines, combustors occurring in the internal duct, one before turbines and one between turbines and external and internal duct propelling nozzles. 


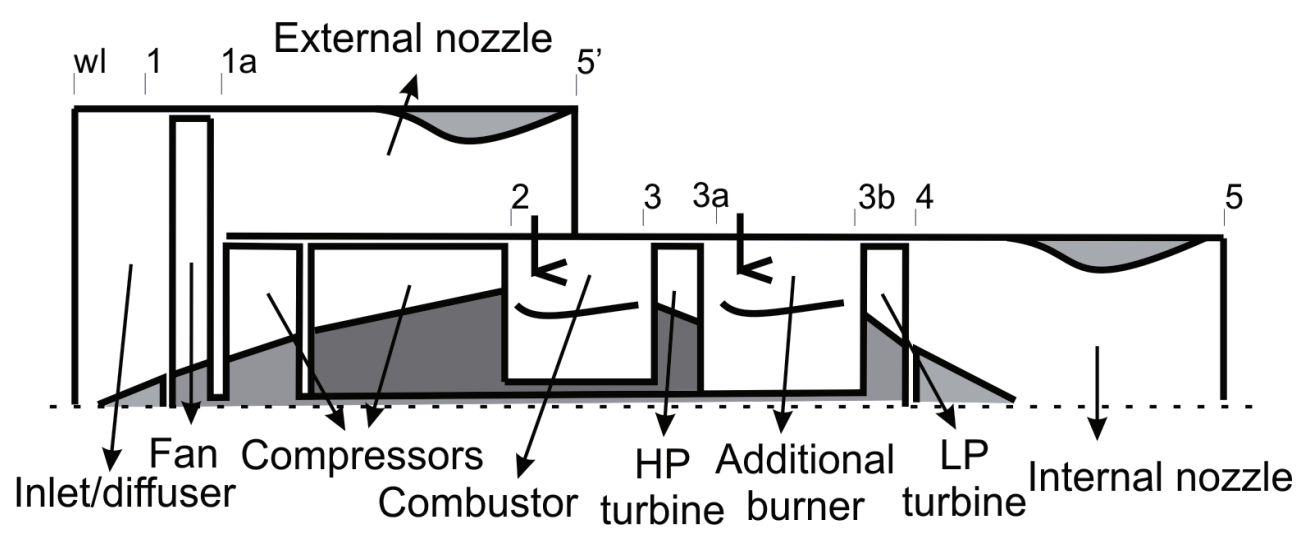

Fig. 1. Turbofan engine with inter-turbine burner scheme

The main reason of such an engine conceptual study is lowering the turbine inlet temperature TIT. In the classical contemporary turbofan, the TIT is about $1700 \mathrm{~K}[1,2,5]$. Such turbine inlet temperature level requires advanced turbine disc and blades cooling systems and a lot of air should be extracted from the mine stream for cooling $[1,3]$. All of this lowers engine effectiveness, first of all by some air exclusion from compressor which causes lowering of combustion energy and turbine power, and secondly by turbine efficiency lowering $[2,3,11]$. On the other hand, a simpler structure of uncooled turbine blades and discs is cheaper for manufacturing, more reliable and durable and increases the time of safe operation [1].

Proposed engine could achieve compared thrust to classical turbofan but with lower TIT level, at about $1300 \mathrm{~K}$. It is done by the additional combustor between turbines. The reheating provides similar energy of gas inflow to second turbine, even though TIT of high-pressure turbine is lower than in the contemporary turbofan engine. This is presented in Fig. 2, where the classical turbofan and proposed the two combustors turbofan engine cycles are compared.
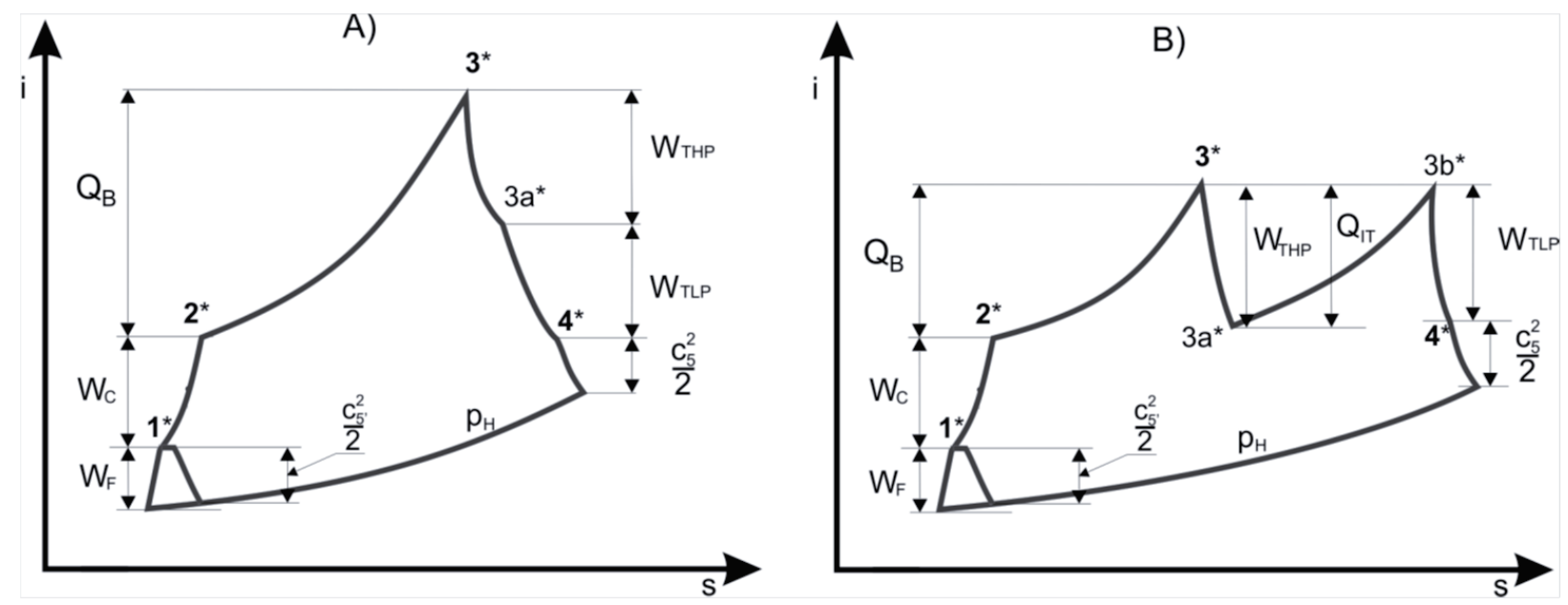

Fig. 2. i-s diagram A) classical turbofan engine, B) turbofan engine with two combustors

\section{Mathematical model of two-combustor engine}

Based on charts presented in Fig. 1 and 2B the mathematical model of two-combustor turbofan was elaborated. The total heat added to the engine is a sum of heat added in the main burner $\mathrm{Q}_{\mathrm{B}}$ and in the burner between turbines $\mathrm{Q}_{\mathrm{IT}}$ :

where:

$$
Q_{t}=Q_{B}+Q_{I T}
$$

$\mathrm{Q}$ - heat added into the engine, 
indexes:

$\mathrm{t}$ - total,

$\mathrm{B}$ - the main combustor,

IT - the burner between turbines (inter turbines).

Heat added in the individual combustor is calculated as:

$$
Q=\frac{m_{f}}{m_{I}} h \eta_{B}=C_{p}\left(T_{B 2}-T_{B !}\right)
$$

where:

$$
\begin{array}{ll}
m_{f}, m_{I} & - \text { fuel mass flow, air core engine mass flow, } \\
\mathrm{h} & - \text { fuel heat value, } \\
\eta_{B} & \text { - burner efficiency, } \\
\mathrm{C}_{\mathrm{p}} & \text { - specific heat, } \\
\mathrm{T} & \text { - total temperature, } \\
\mathrm{B} 1 & \text { - burner inlet, } \\
\mathrm{B} 2 & \text { - burner outlet. }
\end{array}
$$

Consumption of fuel mass flow is estimated from the relation:

$$
\sum m_{f}=m_{f_{-} B}+m_{f_{-} I T}=\left(m_{I} Q_{t}\right) /\left(h\left(\eta_{B}+\eta_{I T}\right)\right) .
$$

The engine thrust is calculated as:

$$
F=m_{5} c_{5}+m_{I} \alpha c_{5 \prime}-m_{I}(1+\alpha) V .
$$

Specific thrust is calculated as:

$$
F_{S}=\left(\frac{m_{5}}{m_{I}} c_{5}+\alpha c_{5 \prime}-(1+\alpha) V\right) /(1+\alpha),
$$

where:

$F \quad-$ thrust,

$F_{S} \quad-$ specific thrust,

$m_{5} \quad$ - fumes mass flow of internal duct exit,

$\mathrm{c}_{5}, \mathrm{c}_{5}, \quad-$ velocity of jet stream in the internal and external nozzle exit,

$\alpha \quad$-bypass ratio,

$\mathrm{V} \quad$ - flight speed.

Specific fuel consumption is evaluated as:

$$
S_{f}=\sum m_{f} / F .
$$

Specific thrust and specific fuel consumption are very important parameters determined engine performance [10]. High specific thrust indicates that engine internal processes are efficient and the engine cycle parameters are properly chosen. Low specific fuel consumption determines that the engine internal process is efficient by the way; fuel consumption cost is not so great.

\section{Numerical model and simplification of engine performance calculation}

Engine is represented by numerical model consisted of functional blocks represented main engine components. Block structure of the engine is presented in Fig. 3. All components are connected by functional and structural relationship as in real engine.

Functional blocks of the engine components include typical numerical description of the flowthermal processes occurring in them, as it is presented in [10]. The additional combustor is modelled as the main combustor, but worse working conditions are described by lower burning efficiency. In this work, additional combustor efficiency was assumed 0.965 , while the main combustor efficiency was assumed 0.985 . 
Globally engine work conditions are represented by characteristic parameters like pressure ratio of fan and compressors and temperature ratio of combustors. Other important factors, which determine engine performance, are engine losses, which are characterized by coefficients described real processes derogation from ideal processes. On that basis fan, compressor and turbine process imperfection is characterized by polytropic efficiency. For inlet, propelling nozzles, combustors and other ducts the pressure losses coefficient is applied. The turbines are not internal cooled $($ TIT $=1300 \mathrm{~K})$, therefore their efficiency was assumed higher than in the classical turbofan engine. Polytropic efficiency of both turbines was assumed as 0.9.

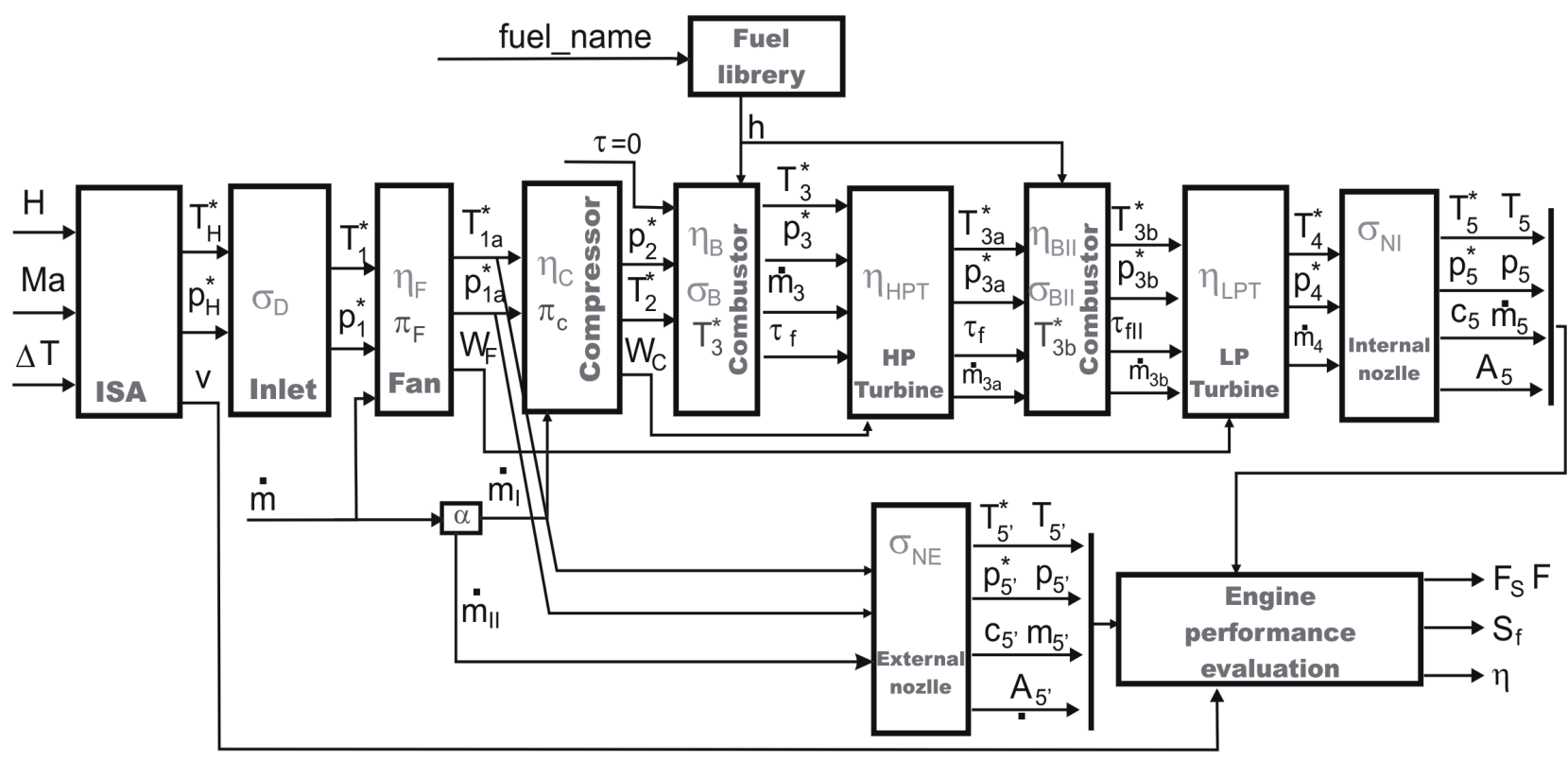

Fig. 3. Blocs structure of double combustor turbofan engine model

The assumption of the turbines without internal cooling allowed reducing air mass extraction from engine. In calculated engine air mass, extraction was omitted.

Ambient conditions are modelled according ISA standard for the assumed altitude.

\section{Calculation of engine work parameters for static conditions on the ground}

The calculations of engine performances were done for static conditions on the ground at the beginning. The engine main parameters were assumed as optimal work conditions published in the paper [4]. By this way both turbines inlet temperature were $1300 \mathrm{~K}$, bypass ratio $(\alpha=6)$, fan pressure ratio $\left(\pi_{\mathrm{F}}=1.6\right)$, low-pressure compressor pressure ratio $\left(\pi_{\mathrm{LP}}=1.7\right)$, high-pressure compressor pressure ratio $\left(\pi_{\mathrm{HP}}=10\right)$.

The results of calculation are: engine specific thrust $\mathrm{F}_{\mathrm{s}}=300 \mathrm{~N}^{*} \mathrm{~s} / \mathrm{kg}$, specific fuel consumption $\mathrm{S}_{\mathrm{f}}=0.4 \mathrm{~kg} / \mathrm{daN} / \mathrm{h}$, internal nozzle jet speed $\mathrm{c}_{5}=460 \mathrm{~m} / \mathrm{s}$ and external nozzle jet speed $\mathrm{c}_{5},=270 \mathrm{~m} / \mathrm{s}$. Pressure and temperature distribution in engine cut sections are presented in Fig. 4.

Presented results show that the engine work parameters are similar to classical turbofan engine. Specific thrust about $300 \mathrm{Ns} / \mathrm{kg}$ is typical for high bypass ratio turbofans. Specific fuel consumption about $0.41 \mathrm{~kg} / \mathrm{daN} / \mathrm{h}$ is compared with this parameter of high bypass ratio turbofans.

The temperature and pressure chart shows the typical course of these parameters with one exception. The temperature increases between turbines in an additional combustor and pressure slightly decreases in it. Thanks to it, the energy of stream inflow into the low-pressure turbine is enough for propelling a large fan and a low-pressure compressor, even that the maximum temperature in an engine is limited to $1300 \mathrm{~K}$. 


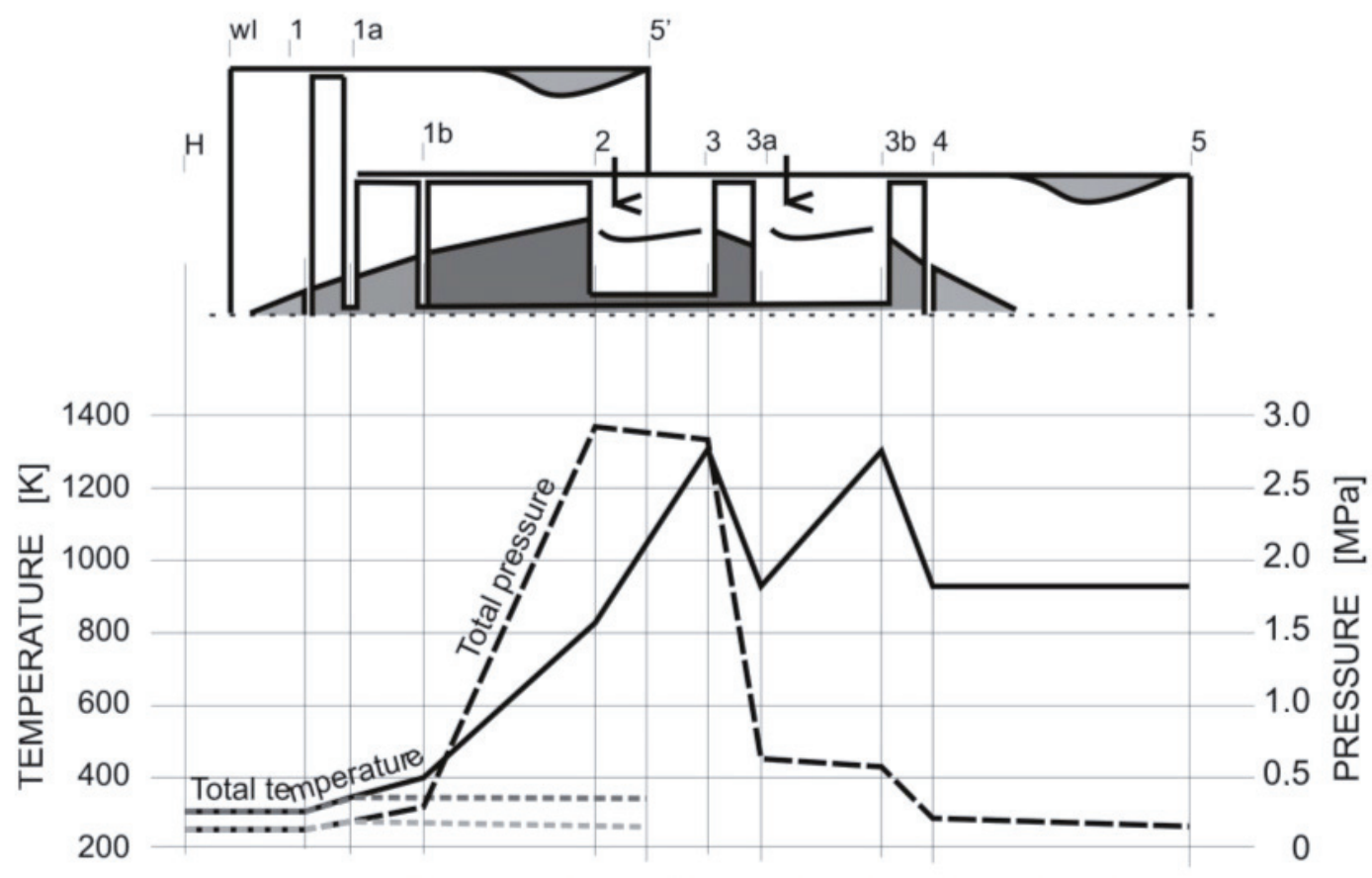

Fig. 4. Total temperature and total pressure in engine cut sections

\section{Engine performance for different flight conditions}

Another step it was the engine flight conditions evaluations. It was assumed the static pressure and temperatures vs. altitude is according to the ISA standard. The flight speed condition was defined as Mach number. For large turbofans, flight speed is limited to 0.8-0.9 Ma, so conceptual engine was analysed in flight speed range 0-0.8 Ma. The altitude was analysed from 0 to $13 \mathrm{~km}$ because it is the range of such engine operation.

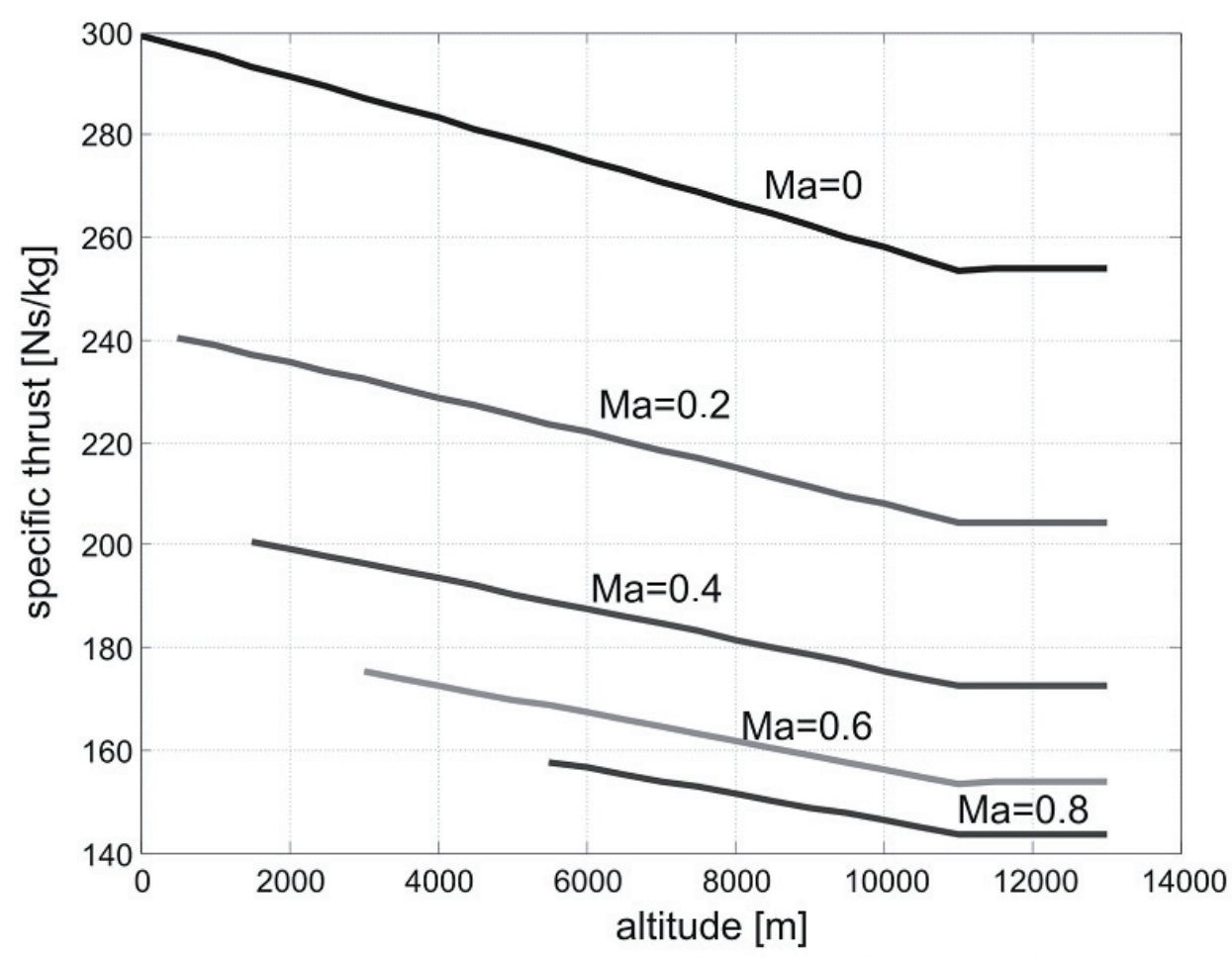

Fig. 5. Specific thrust vs. altitude and flight speed 
In Fig. 5, the relation of specific thrust vs. altitude and flight speed is presented. The results are similar to large turbofan engine performances. Specific thrust decreases with altitude and flight speed growth. $11 \mathrm{~km}$ is a limit of altitude impact on engine specific thrust. Specific thrust is fixed at a constant level above this altitude level. It is caused by ambient temperature, which is fixed at a constant level above $11 \mathrm{~km}$.

Specific fuel consumption vs. altitude and flight speed is presented in Fig 6. The results show the altitude up to $11 \mathrm{~km}$ causes a decrease of specific fuel consumption. Above this altitude, it is fixed on the constant level. Higher value of flight speed increases specific fuel consumption. It is a typical situation for large turbofans [10].

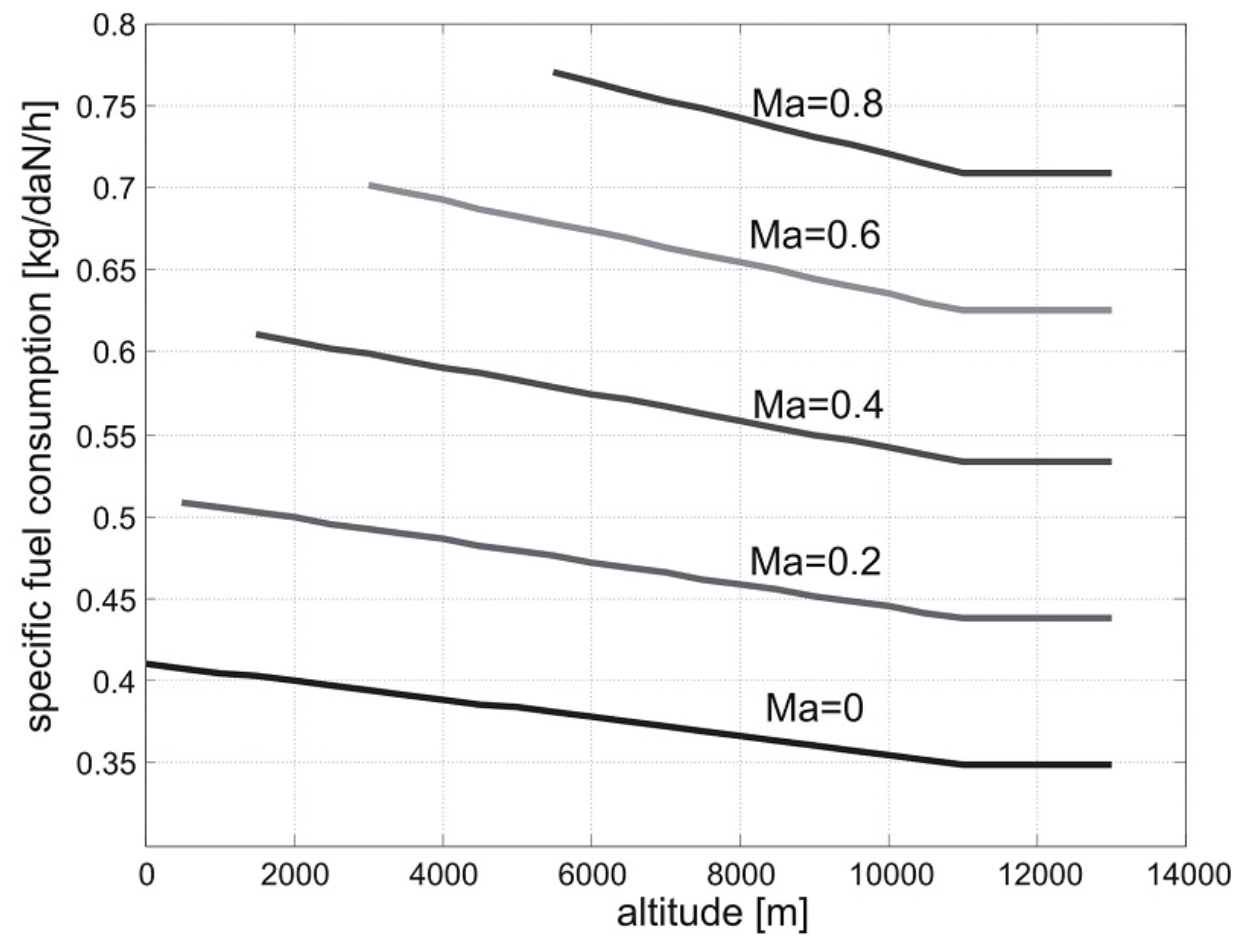

Fig. 6. Specific fuel consumption vs. altitude and flight speed

Presented charts in Fig. 5, 6 show that for higher flight speed results do not exist for low altitude levels. It is caused by ram effect. Ram compression cause growth of temperature in the fan inlet. This is a function of flight Mach number:

$$
T_{t 1}=T_{H}\left(1+\frac{k-1}{2} M a^{2}\right)
$$

where:

$T_{t 1}-$ total temperature in the fan inlet,

$T_{H}$ - ambient temperature,

$M a$ - flight Mach number.

The increase of fan inlet temperature caused by flight speed increases the temperature after compressor. To ensure an adequate level of power produced by fan and compressor propelling turbine the turbine inlet temperature should be increased above the allowed level of $1300 \mathrm{~K}$. This restriction limits engine work with high speed on the low altitude. Ambient temperature decreases with altitude growth therefore an altitude level exists where the ambient temperature is sufficiently low for some flight speed and the turbine inlet temperature is not exceeded.

Theoretical analysis of ambient condition influence the specific thrust and specific fuel consumption of the turbofan engine and confirmed by the results. Both parameters are a function of ambient temperature only as it is written below: 


$$
\begin{aligned}
& F_{S_{-} H}=F_{S_{-} 0} \sqrt{\frac{T_{H}}{T_{0}}}, \\
& S_{f_{-} H}=S_{f_{-} 0} \sqrt{\frac{T_{H}}{T_{0}}},
\end{aligned}
$$

where:

$F_{S_{-} H}, F_{S_{-} 0}$ - engine specific thrust on $\mathrm{H}$ and 0 altitude,

$S_{f_{-} H}, S_{f_{-} 0}-$ engine specific fuel consumption on $\mathrm{H}$ and 0 altitude,

$T_{H}, T_{0} \quad-$ ambient temperature on $\mathrm{H}$ and 0 altitude

An ambient temperature decrease with altitude increasing up to $11 \mathrm{~km}$, so according equations 8 and 9 specific thrust and specific fuel consumption should go down for higher altitude to $11 \mathrm{~km}$.

\section{Conclusions}

The presented results show that the idea of two combustors engine allow to achieve the aircraft propulsion of similar features to the classical turbofan. The differences are connected with additional combustor and lower level of turbine inlet temperature. The profits connected with it are significant - the simpler manufacturing techniques, lower cost of production and maintenance, higher durability, lower emission etc. It is caused mainly by turbine inlet temperature limit to 1300 $\mathrm{K}$, where the turbine internal cooling system is not required and the condition of turbine work significantly improves.

The additional combustor allows increasing low-pressure turbine inlet temperature for production of sufficient power level for fan and low-pressure compressor. This way it is compensated lower energy of gas leaving high-pressure turbine, when the HP turbine inlet temperature is limited.

The analysis shows the main parameters of double combustors engine are close to the similar classical turbofan engine. Specific thrust and specific fuel consumption are on the similar level. Ambient conditions influence the engine performance typically, caused the two combustors engine map is similar two other turbojet and turbofan engine.

The concept of the engine seems to be more interesting for future investigation and development. The future analysis among other things will concentrate on an engine work with second combustor excluded. It is known that the temperature change influences the gas density and for stable work of engine the sections area should be changed.

\section{References}

[1] Daggett, D., Hadaller, O., Hendricks, R., Walther, R., Alternative Fuels and their Potential Impact on Aviation, ICAS 2006-5.8.2, 25th ICAS Congress, 2006.

[2] Horlock, J. H., Watson, D. T., Jones, T. V., Limitations on Gas Turbine Performance Imposed by Large Turbine Cooling Flow, Journal of Engineering for Gas Turbines and Power, Vol. 123, pp. 487-494, 2001.

[3] Jakubowski, R., Modeling and analysis of jet engine with cooling turbine, Journal of KONES, Vol. 19, No. 2, p. 235-243.

[4] Lefebvre, A. H., Gas Turbine Combustion, $3^{\text {th }}$ ed., Taylor and Francis Group, LLC. 2010.

[5] Liew, K. H., Urip, E., Yang, S. L., Parametric Cycle Analysis of a Turbofan with Interstage Turbine Burner, Journal of Propulsion and Power, Vol. 21, No. 3, 2005.

[6] Liew, K. H., Urip, E., Yang, S. L., Mattingly, J. D., Marek, C. J., Performance Cycle Analysis of a Two-spool Separate-exhaust Turbofan with Interstage Turbine Burner, Journal of Propulsion and Power, Vol. 22, No. 2, pp. 411-416, 2006.

[7] Liu, F., Sirignano, W. A., Turbojet and Turbofan Engine Performance Increases Through 
Turbine Burners, Journal of Propulsion and Power, Vol. 17, No. 3, pp. 695-705, 2001.

[8] Sirignano, W. A., Liu, F., Performance Increases for Gas-Turbine Engines Through Combustion Inside the Turbine, Journal of Propulsion and Power, Vol. 15, No. 1, pp 111-118, 1999.

[9] Walsh, P. P., Fletcher, P., Gas Turbine Performance, 2nd ed., Blackwell Publishing and ASME, Fairfield, pp. 227 and 282, NJ 2004.

[10] Young, J. B., Wilcock, R. C., Modeling the Air-Cooled Gas Turbine: Part 1 - General Thermodynamics, Journal of Turbomachinery, Vol. 124, No. 2, pp. 207-213, 2002. 